\title{
CDISC SDTM Subject Status Test Name Terminology
}

National Cancer Institute

\section{Source}

National Cancer Institute. CDISC SDTM Subject Status Test Name Terminology. NCI

Thesaurus. Code C124306.

Terminology associated with the subject status test name codelist of the Clinical Data Interchange Standards Consortium (CDISC) Study Data Tabulation Model (SDT M). 